\title{
Procolipase Gene: No Association with Early-Onset Obesity or Fat Intake
}

\author{
Anne-Kathrin Wermter ${ }^{\text {aa }} \quad$ André Scherag ${ }^{\text {b,ca }} \quad K^{2}$ atja Hölter ${ }^{\text {aa }} \quad$ Kathrin Reichwald $^{\text {d,ea }}$ \\ Peter Lichtner ${ }^{f}$, Wolfgang Siegfried ${ }^{g}$ John Blundell $^{\mathrm{h}}$ Clare Lawton $^{\mathrm{h}}$ Stephen Whybrow ${ }^{\mathrm{i}}$ \\ James Stubbs ${ }^{j}$ Jonathan R. Arch ${ }^{k}$ Thomas Meitinger ${ }^{f, l} \quad$ Matthias Platzer $^{e}$ Anke Hinney ${ }^{d}$ \\ Johannes Hebebrand ${ }^{d}$
}

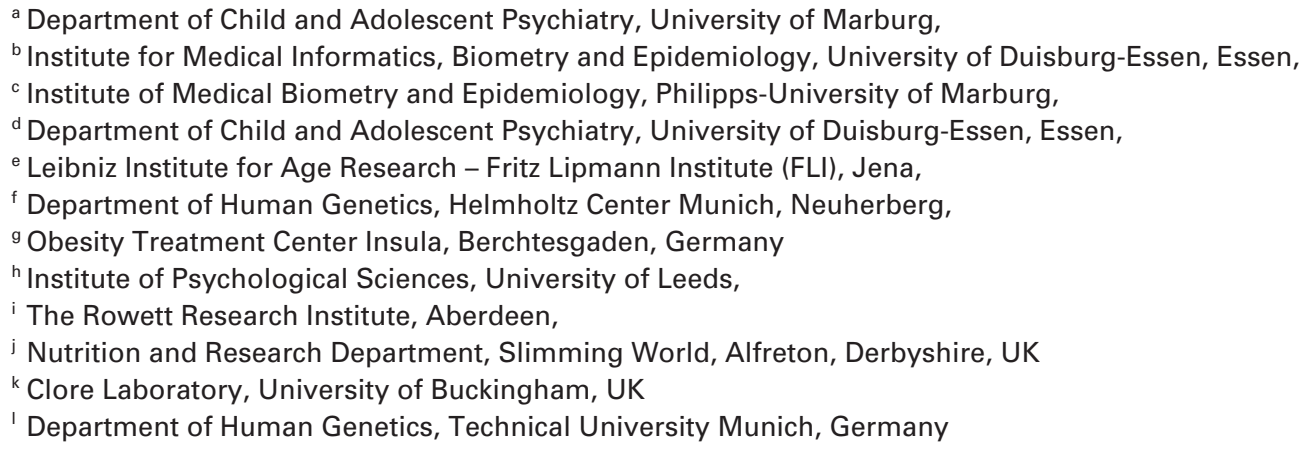

\section{Key Words}

Enterostatin · Body weight regulation · Association . Single nucleotide polymorphism · Mutation screen

\section{Summary}

Background: Several lines of evidence indicate an involvement of procolipase (CLPS) or its derivative enterostatin in dietary fat absorption, regulation of fat intake, and body weight in rodents. We explored the relationship between genetic variation in CLPS, early-onset obesity and fat intake in humans. Methods: We screened the CLPS in 93 extremely obese children and adolescents and 96 underweight young adults for sequence variations and genotyped single nucleotide polymorphisms (SNPs) in extremely obese children and adolescents, healthy normal- and underweight young adults and obesity trios. Case-control and family-based association analyses were performed. Results: Five sequence variations were identified: two non-synonymous SNPs: rs2766597 (Leu8Pro), rs41270082 (Arg109Cys); one SNP in the 5'UTR: rs3748050; one intronic SNP: rs3748051; and one infrequent novel non-synonymous variant: Arg55His. For rs2766597, rs3748050, and rs3748051 we obtained no evidence for an association with obesity in the case-control comparison. For rs41270082 there was a trend for association which could not be substantiated in the family-based association analysis. Additionally, we found no association in subgroup analyses pertaining to the extremely obese children and adolescents in the lowest and highest quartile of the percentage of energy consumed as fat. Conclusions: We found no evidence for an association of CLPS SNPs rs2766597, rs41270082, rs3748050, and rs3748051 with obesity or percentage of dietary fat intake.

\section{Introduction}

The colipase preproprotein (CLPS) is present in exocrine pancreatic cells and is secreted into the pancreatic juice [1]. CLPS expression is increased during feeding on fat and might provide a feedback signal for the inhibition of high levels of fat feeding [2]. After activation by trypsin, procolipase is split into the N-terminal pentapeptide enterostatin and the 90 amino acid (aa) mature protein colipase [3]. The role of colipase is to restore the activity of pancreatic lipase in the presence of inhibitory substances like bile acids [4]. Hence, it may be essential for the efficient digestion of dietary fat.

$\mathrm{Clps}^{-1-}$ mice show decreased postnatal survival and weight gain, steatorrhea on a high-fat diet, and reduced body weight com-

\begin{tabular}{ll}
\hline KARGER & ( ) 2009 S. Karger GmbH, Freiburg \\
Fax +49 761 4520714 & Accessible online at: \\
Information@Karger.de & www.karger.com/ofa \\
www.karger.com &
\end{tabular}


Table 1. Anthropometric data of extremely obese children and adolescents (cases), underweight young adults (controls) and obese trio families (obese children and adolescents and both biological parents $)^{\mathrm{a}}$

\begin{tabular}{|c|c|c|c|c|c|}
\hline Study group & Number & Female/male & BMI, $\mathrm{kg} / \mathrm{m}^{2}$ & Age, years & Fat intake $^{\mathrm{b}}, \%$ \\
\hline $\begin{array}{l}\text { Case sample of obese children and } \\
\text { adolescents }\end{array}$ & 304 & $163 / 141$ & $\begin{array}{l}33.47 \pm 6.27 \\
(28.74 ; 32.46 ; 36.73)\end{array}$ & $\begin{array}{l}13.98 \pm 2.35 \\
(12.53 ; 14.02 ; 15.57)\end{array}$ & ND \\
\hline $\begin{array}{l}\text { Obese children and adolescents, } \\
\text { LF consumer cases }\end{array}$ & 45 & $29 / 16$ & $\begin{array}{l}31.07 \pm 1.99 \\
(27.10 ; 29.66 ; 33.49)\end{array}$ & $\begin{array}{l}13.57 \pm 2.18 \\
12.41 ; 13.5314 .91)\end{array}$ & $\begin{array}{l}32.11 \pm 4.15 \\
(30.00 ; 33.00 ; 35.00)\end{array}$ \\
\hline $\begin{array}{l}\text { Obese children and adolescents, } \\
\text { HF consumer cases }\end{array}$ & 48 & $20 / 28$ & $\begin{array}{l}32.15 \pm 5.44 \\
(27.30 ; 30.69 ; 35.90)\end{array}$ & $\begin{array}{l}13.50 \pm 1.98 \\
12.48 ; 13.28 ; 15.00)\end{array}$ & $\begin{array}{l}45.46 \pm 2.24 \\
(43.00 ; 45.50 ; 47.00)\end{array}$ \\
\hline $\begin{array}{l}\text { Control sample of healthy underweight } \\
\text { individuals }\end{array}$ & 325 & $157 / 168$ & $\begin{array}{l}19.36 \pm 1.99 \\
(17.72 ; 18.95 ; 20.79)\end{array}$ & $\begin{array}{l}25.16 \pm 3.48 \\
(22.63 ; 24.73 ; 26.80)\end{array}$ & ND \\
\hline $\begin{array}{l}\text { Obese offspring } \\
\text { (children and adolescents) }\end{array}$ & 365 & $156 / 209$ & $\begin{array}{l}31.81 \pm 6.04 \\
(27.59 ; 31.00 ; 34.85)\end{array}$ & $\begin{array}{l}13.75 \pm 3.08 \\
(12.14 ; 13.84 ; 15.58)\end{array}$ & ND \\
\hline Parents & 730 & $365 / 365$ & $\begin{array}{l}29.96 \pm 6.22 \\
(25.59 ; 29.10 ; 33.17)\end{array}$ & $\begin{array}{l}42.68 \pm 6.47 \\
(38.33 ; 42.47 ; 46.32)\end{array}$ & ND \\
\hline
\end{tabular}

${ }^{a}$ Values are given as absolute frequencies, mean \pm SD and 1st, 2nd and 3rd quartile (in parentheses). Note that not all individuals were genotyped for all markers.

${ }^{\mathrm{b}}$ As measured by the Leeds Food Frequency Questionnaire.

$\mathrm{HF}=$ High fat; $\mathrm{LF}=$ low fat; ND = not determined.

pared to their $\mathrm{Clps}^{-1+}$ and wild-type littermates [5]. This indicates that colipase, or its precursor procolipase, has additional functions in dietary fat digestion and body weight regulation in the period after birth when pancreatic lipase is not expressed. Studies involving the administration of enterostatin, either centrally or peripherally, demonstrated a dose-dependent and specific inhibition of fat intake in rats given a choice between fat, carbohydrate and protein [6], or an inhibition of high-fat intake as opposed to low-fat intake in a two-choice situation [7]. The inhibition of fat intake by enterostatin has been characterized as an induction of early satiety [8]. Enterostatin acts through an interaction with a postulated $\mu$-opioid pathway that affects reward perception and the production of ATP through an interaction with the $\beta$-subunit of F1F0 ATPase $[9,10]$. In addition, there is evidence that enterostatin inhibits dietary fat intake through a melanocortin signaling pathway [11]. The effect of substances that stimulate fat intake, such as galanin [8], opioids [12-14] and glucocorticoid hormones [15], could be reduced by enterostatin treatment. In long-term studies enterostatin was shown to decrease food intake and reduce body fat and body weight in rodents on a high-fat diet [16, 17]. Reduction of insulin and stimulation of corticosterone secretion [17, 18], sympathetic stimulation of brown adipose tissue [19], and an increased thermogenesis [20] have been suggested to contribute to these effects. In humans, it was suggested that enterostatin secretion might be reduced in obesity, in both fasting and postingestive states [2, 21]. However, in clinical trials intravenous [22] and oral [23] administration of enterostatin did not reduce food intake in human subjects.

The human procolipase gene (CLPS) is localized on chromosome 6 p21.31 and encodes a 112 aa preprotein. Given the presumed importance of CLPS for the regulation of fat intake and body weight regulation, we investigated if genetic variation in the CLPS is associated with early-onset obesity and fat intake in German samples comprising extremely obese children and adolescents and lean controls or nuclear families with extremely obese offspring.

\section{Patients and Methods}

Study Subjects

The ascertainment strategy was previously described in detail [24]. All extremely obese children and adolescents had an age- and gender-specific BMI percentile of 90 or higher as discussed previously [25] (98\% had a percentile $>99$ ). However, only parts of the total sample (table 1) were genotyped for each marker (table 2). The total case sample comprised 304 extremely obese German children and adolescents who were recruited in hospitals specialized for the treatment of young in-patients with extreme obesity. 93 extremely obese children and adolescents, a subgroup of cases, were classified into 48 habitual high-fat (HF; $43-51 \%$ energy from fat) and 45 low-fat (LF; 21-36\% energy from fat) consumers [27]. The percentage of energy consumed as fat was assessed using the 'Leeds Food Frequency Questionnaire' (Leeds FFQ) [26], which was adapted for German nutritional habits. Consistency of the adapted FFQ was evaluated using a short FFQ validated in Germany [28]. The control sample comprised 325 healthy normal weight and underweight students; about $70 \%$ were lean $(<15$ th percentile). They were recruited at the University of Marburg and reimbursed for their voluntary participation. The genotyped trio family sample included 365 extremely obese children and adolescents and both biological parents. All three samples were independent (table 1). Written informed consent was given by all participants and, in the case of minors, their parents. This study was approved by the Ethics Committee of the University of Marburg and carried out in accordance with the Declaration of Helsinki. 
Table 2. Genotype distributions and association analyses for four CLPS SNPs on chromosome 6 in obese children and adolescents (cases) compared with underweight and normal weight young adults (controls). In addition a subgroup of the obese children and adolescents was derived from the quartiles of percentage of energy consumed fat (LF vs. HF consumers) and compared with each other or with the controls ${ }^{\mathrm{a}}$

\begin{tabular}{|c|c|c|c|c|c|c|c|c|c|c|c|c|c|}
\hline \multirow[t]{2}{*}{$\begin{array}{l}\text { Marker } \\
\text { genotypes }\end{array}$} & \multirow{2}{*}{$\begin{array}{l}\text { Physical } \\
\text { position (bp) } \\
\text { dbSNP127 }\end{array}$} & \multicolumn{2}{|c|}{ Cases } & \multicolumn{2}{|c|}{ Controls } & \multirow{2}{*}{$\begin{array}{l}\text { OR estimate } \\
\text { p value } \\
\text { Cases vs. } \\
\text { controls }\end{array}$} & \multicolumn{2}{|c|}{$\begin{array}{l}\text { LF consumer } \\
\text { cases }\end{array}$} & \multicolumn{2}{|c|}{$\begin{array}{l}\text { HF consumer } \\
\text { cases }\end{array}$} & \multicolumn{3}{|l|}{$\begin{array}{l}\text { OR estimate } \\
\text { p value }\end{array}$} \\
\hline & & $n$ & $\%$ & $n$ & $\%$ & & $\%$ & $n$ & $\%$ & $n$ & LF vs. HF & $\begin{array}{l}\text { LF vs. } \\
\text { controls }\end{array}$ & $\begin{array}{l}\text { HF vs. } \\
\text { controls }\end{array}$ \\
\hline rs2766597 & 35873021 & & & & & & & & & & & & \\
\hline $\mathrm{CC}$ & & 0 & 0.0 & 0 & 0.0 & 0.35 & 0 & 0.0 & 0 & 0.0 & ND & ND & 0.70 \\
\hline $\mathrm{TC}$ & & 2 & 2.1 & 19 & 5.9 & $(0.04 ; 1.48)$ & 0 & 0.0 & 2 & 4.2 & & & $(0.08 ; 3.07)$ \\
\hline TT & & 93 & 97.9 & 306 & 94.1 & 0.22 & 45 & 100.0 & 46 & 95.8 & 0.53 & 0.16 & 0.95 \\
\hline rs3748050 & 35873046 & & & & & & & & & & & & \\
\hline GG & & 1 & 1.2 & 8 & 3.9 & 0.82 & 1 & 2.2 & 0 & 0.0 & 0.67 & 0.71 & 1.07 \\
\hline $\mathrm{AG}$ & & 35 & 42.2 & 91 & 44.4 & $(0.47 ; 1.41)$ & 17 & 37.8 & 24 & 50.0 & $(0.27 ; 1.64)$ & $(0.37 ; 1.38)$ & $(0.54 ; 2.11)$ \\
\hline AA & & 47 & 56.6 & 106 & 51.7 & 0.53 & 27 & 60.0 & 24 & 50.0 & 0.45 & 0.40 & 0.96 \\
\hline rs3748051 & 35872921 & & & & & & & & & & & & \\
\hline GG & & 1 & 1.2 & 8 & 3.9 & 0.83 & 1 & 2.6 & 0 & 0.0 & 0.65 & 0.64 & 0.98 \\
\hline $\mathrm{AG}$ & & 36 & 43.4 & 93 & 45.4 & $(0.48 ; 1.43)$ & 14 & 35.9 & 21 & 48.8 & $(0.25 ; 1.72)$ & $(0.29 ; 1.37)$ & $(0.48 ; 2.00)$ \\
\hline AA & & 46 & 55.4 & 104 & 50.7 & 0.55 & 24 & 61.5 & 22 & 51.2 & 0.47 & 0.29 & 1.00 \\
\hline rs41270082 & 35870915 & & & & & & & & & & & & \\
\hline $\mathrm{TT}$ & & 0 & 0.0 & 0 & 0.0 & 3.45 & 0 & 0.0 & 0 & 0.0 & 1.07 & 5.38 & 5.02 \\
\hline CT & & 12 & 4.4 & 3 & 1.3 & $(0.91 ; 19.25)$ & 3 & 6.7 & 3 & 6.3 & $(0.14 ; 8.44)$ & $(0.69 ; 41.18)$ & $(0.65 ; 38.4)$ \\
\hline $\mathrm{CC}$ & & 262 & 95.6 & 226 & 98.7 & 0.07 & 42 & 93.3 & 45 & 93.7 & 1.00 & 0.12 & 0.13 \\
\hline
\end{tabular}

ND $=$ Not determined

${ }^{a}$ Odds ratios (OR) estimates with $95 \%$ confidence intervals in parenthesis and p values were calculated under a dominant genetic model with the minor allele as risk allele.

\section{Molecular Genetic Methods}

We designed three primer pairs to amplify the entire coding region and splice sites of CLPS. Primers were derived from the genomic sequence (GenBank accession number: NT_007592; www.ncbi.nlm.nih.gov) as follows: CLPS E1-F: 5'-GGT CAG GGC CCC TTT TAT AG-3' and CLPS E1-R: 5'-TCA GAG GTC AAG GTC CAA GC-3': 236 bp CLPS E1 amplicon. CLPS E2-F: 5'-TGG GTA CAG GTC TGA ATG GA-3' and CLPS E2-R: 5'-GTG TTC AGG GCC CTA CTC C-3': 250 bp CLPS E2 amplicon. CLPS E3-F: 5'-AGG GGA CAA GTG ATG TCC AA-3' and CLPS E3-R: 5'-GCC TAC AGC ATT CTG GGC TA-3': 239 bp CLPS E3 amplicon. Polymerase chain reaction (PCR) was performed according to standard protocols. For the mutation screen, single strand conformation polymorphism analysis (SSCP) was performed as described previously [29]. All amplicons with SSCP patterns deviant from the wild-type pattern were sequenced as described previously [29]. To genotype Arg55His and rs41270082, a PCR with subsequent diagnostic restriction fragment length polymorphism analyses (RFLP) was performed. To genotype Arg55His, CLPS E2 amplicon was digested by Fau I (NEB; G-allele: 150 bp and $100 \mathrm{bp}$, A-allele 250 bp). To genotype rs41270082, CLPS E3 amplicon was digested by Fok I (NEB; C-allele: 239 bp, T-allele 183 bp and 56 bp). To genotype rs3748050 and rs3748051 we performed a tetra-primer ARMS-PCR [30] with the following primers:

- rs3748050 (50-i-F: 5'-CAC ACC AGC TGT CCC ACG CA-3', 50-I$R: 5^{\prime}$-CAG GAG GAT CAG GAT CTT CTC CAT TGC-3', 50-o-F: 5'-CCA CAG CAG ATT GGC CAC AGC T-3' and 50-o-R: $5^{\prime}$-CCT GCC AGT CCA GGT GGA GAC A-3'). Sizes of the PCR products were $328 \mathrm{bp}$ (outer primer pair), $204 \mathrm{bp}$ (A-allele), and $171 \mathrm{bp}$ (G-allele).
- $\quad$ rs3748051 (51-i-F: 5'-AAG CGC CTC CTG AGT CCA CA-3', 51-i$R$ : $5^{\prime}$-GGT CCA AGC TTA GGA AGT CTT CAG CC-3', 51-o-F: 5'-ACC ACA GCT GGC TCT GTC TCC C-3' and 51-o-R: $5^{\prime}$-CCA GGT TGA GCT GCT GCT CTG A-3'). Sizes of the PCR products were $371 \mathrm{bp}$ (outer primer pair), $198 \mathrm{bp}$ (A-allele) and $219 \mathrm{bp}$ (G-allele).

All PCR products were visualized on ethidium bromide-stained $2.5 \%$ agarose gels. Allele sizes were determined with a molecular weight standard (123 bp ladder, Gibco BRL, Karlsruhe, Germany). Trio analyses for rs41270082 were performed by high-throughput genotyping via matrixassisted laser desorption/ionization, time-of-flight mass spectrometry (MALDI-TOF-MS), employing the homogeneous mass extension protocol provided by the manufacturer (Sequenom, San Diego, CA, US). Assays for the SNP were designed by the SpectroDesigner software (Sequenom). Note that different numbers of individuals were genotyped for each marker such that the numbers in table 1 and table 2 do not correspond, i.e. table 1 indicates the maximum number of individuals that could have been genotyped.

\section{Statistical Analysis}

Differences in genotype frequencies for a dominant genetic model between samples of unrelated subjects were investigated using Fisher's exact test. This genetic model was chosen because most SNPs had rather low minor allele frequencies, leading to a low number of observations per cell in the $2 \times 3$ frequency table. The exact version, i.e. the binomial test of the classical test [31] for transmission disequilibrium, was used for the trio analysis. All genotype distributions in controls and parents were tested for deviations from Hardy-Weinberg equilibrium (HWE) 
using PEDSTATS 0.6.4 [32], and no evidence for such deviations were detected (all $\mathrm{p} \geq 0.01$ ). As there was no evidence for a significant association, no correction for multiple testing was performed. All reported $\mathrm{p}$ values were nominal, two-sided, and exact. In addition, estimated odds ratios and $95 \%$ confidence intervals are provided under the dominant genetic model. For that same genetic model the power of the analysis was assessed with the software QUANTO Version 1.2.3 (http://hydra. usc.edu/gxe) for rs3748050 (HapMap-CEU minor allele frequency $\approx$ $29 \%$ ). Based on this information 200 case-control pairs were estimated to yield a power $>80 \%$ to detect a genetic odds ratio of $1.8(\alpha=0.05$; two-sided). For the 365 trio families the power estimate was $>80 \%$ to detect a genotype relative risk of $1.5(\alpha=0.05$; two-sided $)$. Thus, the association studies were only well powered to detect common diseasepredisposing variants with strong genetic effects.

\section{Results}

The initial mutation screen of the coding sequence of CLPS in 93 extremely obese children and adolescents (a subgroup of the case sample) and 96 healthy lean young adults (a subgroup of the control sample) revealed two previously described missense SNPs (rs2766597 (Leu8Pro) and rs41270082 (Arg109Cys)) and two non-coding SNPs (rs3748050 in the $5^{\prime}$ UTR and rs3748051 in intron 1). In addition, a novel non-synonymous, non-conservative variant (g.1515G>A: Arg55His) was found in one control proband in the heterozygous state. Due to its very low estimated minor allele frequency (MAF $=0.27 \%$ in our sample) and the low statistical power resulting, this variant was not evaluated further in the case-control association analyses. rs41270082 resulted in an Arg to Cys substitution at position 109 of CLPS. The casecontrol analysis revealed some evidence for a difference in T-allele frequencies between cases and controls $(\mathrm{p}=0.07)$. In an attempt to substantiate this finding, we genotyped rs41270082 in the 365 obesity trio families. Only 3 transmissions versus 7 non-transmissions of the T-allele to the obese offspring could be detected by the transmission disequilibrium test $(\mathrm{TDT})(\mathrm{p}=0.34)$. Hence, the initial result was not substantiated; descriptively the potential 'risk allele' was transmitted less frequently to the obese offspring. rs2766597 predicted a non-conservative aa exchange replacing Leu at position 8 of CLPS with Pro (Leu8Pro). Association analyses for rs2766597 and the other two detected SNPs (rs3748050 and rs3748051) revealed no differences in genotype distributions between extremely obese cases and controls (all $\mathrm{p} \geq 0.2$ ).

Finally, we explored in 93 extremely obese individuals whether any of the genotyped SNPs might be more strongly associated with the dichotomized endophenotype 'percent of energy consumed as fat'. None of these additional comparisons revealed any evidence for differences in genotype frequencies between extremely obese patients of the low and high quartile of the percentage of energy consumed as fat (all $p \geq 0.4$ ) or for the comparisons to the lean controls (all $\mathrm{p} \geq 0.1$ ).

\section{Discussion}

To determine the influence of genetic variants within CLPS on early-onset obesity in humans, we systematically screened the coding sequence of CLPS for sequence variations in a total of 189 German, extremely obese, normal or lean individuals. This sample size is sufficient to allow for the detection of common variants (e.g. assuming a minor allele frequency of 0.05 , the total sample size produced a $95 \%$ confidence interval \pm 0.03 ). Two previously described non-synonymous SNPs (rs2766597 and rs41270082) and two non-coding SNPs (rs3748050 in the 5'UTR and rs3748051 in intron 1) were identified along with one novel infrequent missense variant (Arg55His). In our association studies, we initially compared genotype frequencies of these four SNPs in CLPS between extremely obese children and adolescents and lean controls. While no evidence for an association for rs3748050, rs2766597, and rs3748051 was obtained, there was some evidence for an association between the T-allele of rs41270082 and obesity. This SNP, in codon 109 of $C L P S$, results in an Arg to Cys substitution. Since CLPS contains 10 Cys residues, which form 5 disulfide bridges, an additional Cys residue at position 109 may alter the bridge formation and therefore the stability, conformation and/or function of the protein. Because of these potential functional consequences, we performed subsequent TDTs in 365 obesity trios. Tests revealed no evidence for transmission disequilibrium and therefore did not substantiate the initial finding. However, it is possible that this result might only be due to the insufficient power of the family-based approach. Finally, we also assessed whether one of the four variants might be associated with differences in dietary fat consumption of extremely obese individuals defined by upper and lower quartiles within the case sample. As with the main finding, we found no evidence for differences in genotype frequencies between habitual high-fat and low-fat consumers. The same was true for the comparisons with the control group.

Association of rs3748050 and rs3748051 with reduced insulin secretion in non-diabetic Caucasians was recently detected [33]. Furthermore, previous work suggested a contribution of rs41270082 in CLPS to increased susceptibility to type 2 diabetes mellitus in two German study populations [34]. Very recently, evidence for an association with type 2 diabetes was detected in the EPIC-Potsdam cohort by screening for sequence variants in 15 genes involved in fat assimilation [35]. In an in vitro study rs41270082 was found to decrease the function of colipase [36]. So far, in public association databases associations of CLPS variants with obesity traits have not been reported. Studies of the potential implication of CLPS sequence variants in obesity would benefit from further analyses of rs41270082 in larger samples of obese subjects.

In conclusion, this investigation did not detect any common variants in the coding region and 5'UTR of CLPS with a major impact for the development of early onset obesity or habitual fat intake. However, larger samples will be neces- 
sary to assess moderate genetic effects and their relationship to obesity. Even though limited by the small sample size, the present study may thus contribute to meta-analytic approaches addressing the role of the investigated polymorphisms for the development of early-onset extreme obesity.

\section{Acknowledgements}

We thank all probands and their families for their participation. This work was supported by grants from the German Ministry of Education and Research (Bundesministerium für Bildung und Forschung), National Genome Net NGFN2 and plus (01GS0482), DHGP2 grant 01KW0007, EU Framework V (QLK1-CT-2000-00515) and by the Deutsche Forschungsgemeinschaft (DFG; HE 1446/4-1). The Deutsche Forschungsgemeinschaft (DFG) supported the ascertainment of probands and families. The skilful technical assistance of Gerti Gerber and Uta Petz was highly appreciated.

\section{Disclosure}

The authors declared no conflict of interest.

\section{References}

1 Erlanson-Albertsson C: Enterostatin: the pancreatic procolipase activation peptide - a signal for regulation of fat intake. Nutr Rev 1992;50:307-310.

2 Mei J, Bowyer RC, Jehanli AM, Patel G, ErlansonAlbertsson C: Identification of enterostatin, the pancreatic procolipase activation peptide in the in testine of rat: effect of CCK-8 and high-fat feeding. Pancreas 1993;8:488-493.

$\checkmark 3$ Erlanson-Albertsson C, Larsson A: The activation peptide of pancreatic procolipase decreases food intake in rats. Regul Pept 1988;22:325-331.

4 van Tilbeurgh H, Bezzine S, Cambillau C, Verger R, Carriere F: Colipase: structure and interaction with pancreatic lipase. Biochim Biophys Acta 1999; 1441:173-184.

$\checkmark 5$ D'Agostino D, Cordle RA, Kullman J, ErlansonAlbertsson C, Muglia LJ, Lowe ME: Decreased postnatal survival and altered body weight regulation in procolipase-deficient mice. J Biol Chem 2002;277:7170-7177.

6 Okada S, York DA, Bray GA, Erlanson-Albertsson C: Enterostatin (Val-Pro-Asp-Pro-Arg), the activation peptide of procolipase, selectively reduces fat intake. Physiol Behav 1991;49:1185-1189.

7 Erlanson-Albertsson C, Mei J, Okada S, York D, Bray GA: Pancreatic procolipase propeptide, enterostatin, specifically inhibits fat intake. Physiol Behav 1991;49:1191-1194.

8 Lin L, McClanahan S, York DA, Bray GA: The peptide enterostatin may produce early satiety. Physiol Behav 1993;53:789-794.

$\checkmark 9$ Berger K, Winzell MS, Mei J, Erlanson-Albertsson C: Enterostatin and its target mechanisms during regulation of fat intake. Physiol Behav 2004;83:623 630.

10 Park M, Lin L, Thomas S, Braymer HD, Smith PM, Harrison DH, et al: The F1-ATPase beta-subunit is the putative enterostatin receptor. Peptides 2004;25: 2127-2133.

11 Lin L, Park M, York DA: Enterostatin inhibition of dietary fat intake is modulated through the melanocortin system. Peptides 2007;28:643-649.

12 Ookuma K, Barton C, York DA, Bray GA: Effect of enterostatin and kappa-opioids on macronutrient selection and consumption. Peptides 1997; 18:785-791.

13 Lin L, Umahara M, York DA, Bray GA: Betacasomorphins stimulate and enterostatin inhibits the intake of dietary fat in rats. Peptides 1998;19: 325-331.
14 White CL, Bray GA, York DA: Intragastric betacasomorphin(1-7) attenuates the suppression of fat intake by enterostatin. Peptides 2000;21:13771381.

15 Mizuma H, Abadie J, Prasad C: Corticosterone facilitation of inhibition of fat intake by enterostatin (Val-Pro-Asp-Pro-Arg). Peptides 1994;15:447452.

16 Lin L, York DA: Chronic ingestion of dietary fat is a prerequisite for inhibition of feeding by enterostatin. Am J Physiol 1998;275:R619-R623.

17 Okada S, Lin L, York DA, Bray GA: Chronic effects of intracerebral ventricular enterostatin in Osborne-Mendel rats fed a high-fat diet. Physiol Behav 1993;54:325-329.

18 Mei J, Cheng Y, Erlanson-Albertsson C: Enterostatin - its ability to inhibit insulin secretion and to decrease high-fat food intake. Int J Obes Relat Metab Disord 1993;17:701-704.

19 Nagase H, Bray GA, York DA: Effect of galanin and enterostatin on sympathetic nerve activity to interscapular brown adipose tissue. Brain Res 1996;709:44-50.

20 Rippe C, Berger K, Boiers C, Ricquier D, Erlanson-Albertsson C: Effect of high-fat diet, surrounding temperature, and enterostatin on uncoupling protein gene expression. Am J Physiol Endocrinol Metab 2000;279:E293-E300.

21 Prasad C, Imamura M, Debata C, Svec F, Sumar $\mathrm{N}$, Hermon-Taylor J: Hyperenterostatinemia in premenopausal obese women. J Clin Endocrinol Metab 1999;84:937-941.

22 Rossner S, Barkeling B, Erlanson-Albertsson C, Larsson P, Wahlin-Boll E: Intravenous enterostatin does not affect single meal food intake in man. Appetite 1995;24:37-42.

23 Kovacs EM, Lejeune MP, Westerterp-Plantenga MS: The effects of enterostatin intake on food intake and energy expenditure. Br J Nutr 2003;90: 207-214.

24 Hinney A, Lentes KU, Rosenkranz K, Barth N, Roth H, Ziegler A, et al: Beta 3-adrenergicreceptor allele distributions in children, adolescents and young adults with obesity, underweight or anorexia nervosa. Int J Obes Relat Metab Disord 1997;21:224-230.

25 Hebebrand J, Himmelmann GW, Heseker H, Schafer H, Remschmidt H: Use of percentiles for the body mass index in anorexia nervosa: diagnostic, epidemiological, and therapeutic considerations. Int J Eat Disord 1996;19:359-369.
26 Cooling J, Blundell J: Differences in energy expenditure and substrate oxidation between habitual high fat and low fat consumers (phenotypes). Int J Obes Relat Metab Disord 1998;22:612-618.

27 Schauble N, Reichwald K, Grassl W, Bechstein $\mathrm{H}$, Muller HC, Scherag A, et al: Human galanin (GAL) and galanin 1 receptor (GALR1) variations are not involved in fat intake and early onset obesity. J Nutr 2005;135:1387-1392.

28 Rohrmann S, Klein G, Miller A: Validierung eines Kurzfragebogens zur Erfassung von Gesamtfett, gesättigten Fettsäuren, einfach und mehrfach ungesättigten Fettsäuren sowie Cholesterin. Proc German Nutr Soc 2001;3:P13.

-29 Hinney A, Schmidt A, Nottebom K, Heibult O, Becker I, Ziegler A, et al: Several mutations in the melanocortin-4 receptor gene including a nonsense and a frameshift mutation associated with dominantly inherited obesity in humans. J Clin Endocrinol Metab 1999;84:1483-1486.

30 Ye S, Dhillon S, Ke X, Collins AR, Day IN: An efficient procedure for genotyping single nucleotide polymorphisms. Nucleic Acids Res 2001;29:E88.

31 Spielman RS, McGinnis RE, Ewens WJ: Transmission test for linkage disequilibrium: the insulin gene region and insulin-dependent diabetes mellitus (IDDM). Am J Hum Genet 1993;52:506-516.

32 Wigginton JE, Cutler DJ, Abecasis GR: A note on exact tests of Hardy-Weinberg equilibrium. Am J Hum Genet 2005;76:887-893.

33 Weyrich P, Albet S, Lammers R, Machicao F, Fritsche A, Stefan N, Häring HU: Genetic Variability of Procolipase Associates with Altered Insulin Secretion in Non-diabetic Caucasians. Exp Clin Endocrinol Diabetes 2008; DOI: 10.1055/s-20081078733.

34 Lindner I, Helwig U, Rubin D, Li Y, Fisher E, Boeing H, et al: Putative association between a new polymorphism in exon 3 (Arg109Cys) of the pancreatic colipase gene and type 2 diabetes mellitus in two independent Caucasian study populations. Mol Nutr Food Res 2005;49:972-976.

35 Fisher E, Nitz I, Lindner I, Rubin D, Boeing H, Mohlig M, et al: Candidate gene association study of type 2 diabetes in a nested case-control study of the EPIC-Potsdam cohort - role of fat assimilation. Mol Nutr Food Res 2007;51:185-191.

36 D'Silva S, Xiao X, Lowe ME: A polymorphism in the gene encoding procolipase produces a colipase, Arg92Cys, with decreased function against longchain triglycerides. J Lipid Res 2007;48:2478-2484. 